\title{
Treatment Strategy for Post-Traumatic Supraorbital and Supratrochlear Neuroma
}

\author{
A Lee Dellon* \\ Department of Plastic Surgery and Neurosurgery, Johns Hopkins University, Baltimore, Maryland, USA
}

\begin{abstract}
Trauma to the supraorbital ridge is common and long-term sequalae of injury to the supraorbital and supratrochlea nerves is under-appreciated. Blunt trauma from motor vehicle accidents, sports injury, cosmetic surgery, and craniofacial surgery all represent potential sources of injury to these nerves, which are at risk as they traverse a path from intra-orbital to subcutaneous through a bony notch/foramen at the supraorbital ridge. Pain related to these nerves causes migraine headaches, dysesthesias in the forehead, and disability related to medication for chronic pain. A series of 5 patients are presented who represent post-traumatic pain related to these two nerves. Treatment strategies are reviewed. A new operative approach is described in which the proximal end of the supraorbital and the supratrochlear nerves are left within the orbit. Long-term follow-up documents no complications with regard to extraocular muscles and range of motion of the orbit, and significant relief of pain.
\end{abstract}

Keywords: Chronic compression; Blunt trauma; Supra trochlear; Supra orbital

\section{Introduction}

Trauma to the supraorbital ridge is common and long-term sequalae of injury to the Supra Orbital (SO) and Supra Trochlear (ST) nerves is under-appreciated. Blunt trauma from motor vehicle accidents, sports injury, cosmetic surgery, and craniofacial surgery all represent potential sources of injury to these nerves, which are at risk as they traverse a path from intra-orbital to subcutaneous through a bony notch/foramen at the supraorbital ridge.

While the anatomy of the SO and ST is well understood [1-7] management of neuromas of these nerves is poorly described. Pain related to these nerves causes migraine headaches [8,9] dysesthesias in the forehead, and disability related to medication for chronic pain. These problems must be addressed in patients with post-traumatic pain after fractures [5], after elective craniofacial surgery [6], and now in those patients having face transplants [10].

At present, for pain related to chronic compression of the SO and ST nerves, a neurolysis is indicated, and good outcomes have been reported $[8,9,11]$. Only one report of treatment of a neuroma of these nerves has been published [12] The six patients in that series had the proximal nerve end connected to the other through a nerve conduit [12]. This approach carries the risk of the "reconstructed" nerves forming a recurrent neuroma in the region of the supraorbital rim/ eyelid. The present series of patients had a different approach taken to treat their pain; the proximal end of the SO and ST nerves were resected so they lay deep within the orbit.

\section{Methods and Materials}

A retrospective review of the charts of 5 patients with disabling pain related to the SO and ST nerves was carried out. These patients ranged in age from 18 to 67 years, with a mean of 42.2 years. Trauma was due to falls in 2, facial fracture in 1, cosmetic surgery in 1 and being hit by a ball in 1 patient see in Table 1. Each patient had either an MRI or CT scan of the head and neck prior to surgery which did not demonstrate a tumor, blood clot, vascular injury, or multiple sclerosis. In each patient, treatment had included massage, ultrasound, nerve block, and in one, a peripheral nerve stimulator. Four of the five patients were on chronic opioid plus neuropathic pain medication. The two teenagers (aged 18 and 19) had each missed two years of high school. Their pre-operative VAS was a mean of 9.0, range 8 to 10. Each patient had relief of pain with a decrease in the VAS by $\geq 5$ points prior to surgery.

\section{Inclusion criteria}

Each patient had failed to improve with at least one year of medical management, including massage, anti-inflammatory and opiod pain medication, diet change and headache medication directed at altering blood flow, or for "migraines'. Furthermore, each patient had decrease in pain/headache following a nerve block of the SO and ST nerves.

\begin{tabular}{|c|c|c|c|c|c|c|}
\hline Name & Age & $\begin{array}{c}\text { Initial } \\
\text { Injury }\end{array}$ & $\begin{array}{c}\text { Time from } \\
\mathrm{T}^{0} \text { to OR } \\
\text { months }\end{array}$ & Oper done & $\begin{array}{c}\text { Follow up } \\
\text { months }\end{array}$ & Result\{E,G,F,P\} \\
\hline 1 & 19 & Fall, bike & 120 & $\begin{array}{l}\text { R Sox } \\
\text { R STx }\end{array}$ & 34 & $\mathrm{E}$ \\
\hline 2 & 18 & Fall, bench & 148 & $\begin{array}{l}\text { R Sox } \\
\text { R STx }\end{array}$ & 18 & G \\
\hline 3 & 56 & tether ball & 84 & $\begin{array}{l}\text { R Sox } \\
\text { R STx } \\
\text { R ZTx }\end{array}$ & 20 & E \\
\hline 5 & 51 & $\begin{array}{c}\text { WC tire } \\
\text { Rim \& Fx }\end{array}$ & 60 & $\begin{array}{l}\text { R SOx } \\
\text { R STx } \\
\text { R ZTx }\end{array}$ & 24 & $\mathrm{E}$ \\
\hline 57 & $2^{\text {nd } \text { brow }}$ & 36 & $\begin{array}{l}\text { L Sox } \\
\text { L STx }\end{array}$ & 12 & $\mathrm{E}$ \\
\hline
\end{tabular}

$\left(\mathrm{T}^{0}=\right.$ initial injury, $\mathrm{OR}=$ operation, $\mathrm{T}^{0}$ to $\mathrm{OR}=$ duration of symptoms prior to neuroma resection, $R=$ right side, $L=$ left side, $S O x=$ resection supra-orbital nerve, $\mathrm{STx}=$ resection supra-trochlear nerve, $\mathrm{E}=$ excellent, $\mathrm{G}=$ good, $\mathrm{F}=$ fair, $\mathrm{P}=$ poor)

Table 1: Supra Orbital and Trochlear Patient Demographics.

*Corresponding author: A Lee Dellon, 1122 Kenilworth Dr Suite 18, Towson, Maryland, 21204, USA, Tel: 410299 6927; Fax: 410337 0040; E-mail: ALDellon@Dellon.com

Received July 14, 2014; Accepted September 20, 2014; Published September 25, 2014

Citation: Dellon AL (2014) Treatment Strategy for Post-Traumatic Supraorbital and Supratrochlear Neuroma. J Trauma Treat 3: 213. doi:10.4172/2167-1222.1000213

Copyright: ( 2014 Dellon AL. This is an open-access article distributed under the terms of the Creative Commons Attribution License, which permits unrestricted use, distribution, and reproduction in any medium, provided the original author and source are credited. 


\section{Surgical technique}

The patient is placed under general anesthesia. The orbit not having surgery has ophthalmologic ointment placed on the cornea and the upper lid taped closed. The orbit having surgery has the ointment placed on the cornea also. An incision is marked along the supratarsal crease, about 8 to $9 \mathrm{~mm}$ away from the lash margin. $1 \%$ xylocaine with $1: 100,000$ epinephrine injected into this marking in the subcutaneous plane. The incision goes through the skin and orbicularis oculi muscle. Meticulous hemostasis is maintained with a needle point cautery at the lowest possible setting. Magnifying loupes at 3.5x are used. The dissection then goes through the orbital septum into the space below the supraorbital ridge, and both the SO and ST nerves are identified. These nerves are each followed distally, releasing them from their respective bony notch or foramen, and following them distally to the point at which a neuroma can be confirmed. If the nerve is found to be just compressed, a neurolysis is performed instead of resection (Figure 1A-1D).

Once the damaged nerve segment is identified the local anesthetic is injected into the nerve to shield the central nervous system from the pain impulses related to nerve division. The SO and ST nerves are divided and followed distally within the orbit. The globe is gently retracted with a soft malleable retractor. Each nerve is then placed under gentle tension, cauterized within the orbit to prevent bleeding, and then divided just distal to the site of cauterization. The specimen is submitted to pathology. The orbit is inspected to ensure hemostasis. The nerve ends are just allowed to find their own resting place within the orbital contents. The wound is closed with interrupted and/ or continuous 6-0 nylon sutures. Bacitracin and gauze are the only dressing. The patient is cautioned not to bend over for three days to prevent increased pressure in the orbit, and encouraged to sleep on two pillows. The sutures are removed on the $5^{\text {th }}$ day. Once the sutures are removed, the patient is encouraged to shower, allowing the water to come on to the denervated scalp and forehead as a form of desensitization and sensory re-education (Figure 2A-2D).

\section{Results}

There were no post-operative complications. In the patient with the peripheral nerve stimulator, this stimulator was also removed. At a mean of 19.6 months (range 12 to 36 months), none of the patients had any pain with extra-ocular muscle function. There was full range of motion of the glove without pain.

The post-operative VAS score was a mean of 0.6 range 0 to 2 . The Difference between pre-and post-op VAS was significant at the $\mathrm{p}<.001$ level.

\section{Discussion}

This is the first report of the successful treatment of neuromas of the SO and ST nerves by resecting the painful neuromas and placing the proximal ends of each nerve within the orbital cavity. In the patients reported here, not only was the original neuroma pain relieved by this treatment, but there were no complications related to pain with extraocular muscle movement.

One of the potential problems with resecting a neuroma of the SO or ST nerves and leaving the end at the level of the forehead, or supraorbital ridge, or eyelid is that the neuroma can recur. With a recurrent neuroma in one of these superficial locations, rubbing the forehead, or wearing a hat, or helmet while skiing or riding a motorcycle or bike might cause recurrent pain. In order to avoid these potential problems, the orbital cavity as a location for the proximal end of the nerve was considered. In the upper [13] and lower [14] extremity, implanting the proximal end of a nerve into muscle is the preferred approach, but there is not a sufficiently large muscle in the anatomic region of the forehead. In the extremity, implanting a nerve into bone is an option, [15] but in the anatomic region of the forehead, the frontal bone is not sufficiently thick to use this approach (Figure 3A-3D).

The differential diagnosis of compression, versus neuroma, versus frontal migraine related to the SO and ST nerves requires a careful history and physical examination. Clearly, as in the situation with the
A

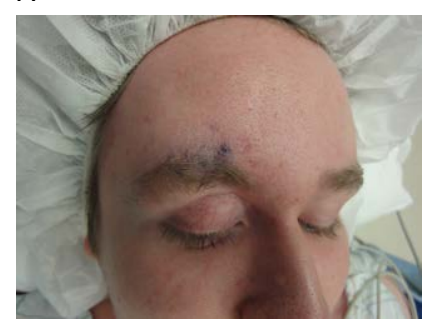

C

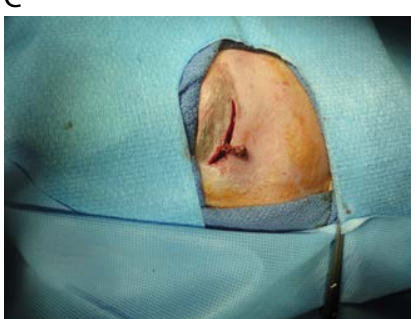

B

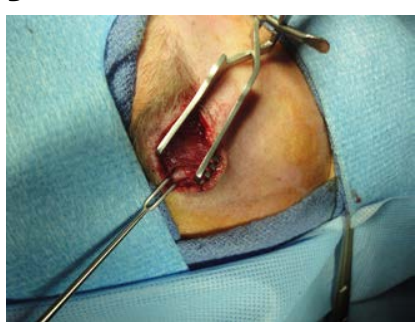

$\mathrm{D}$

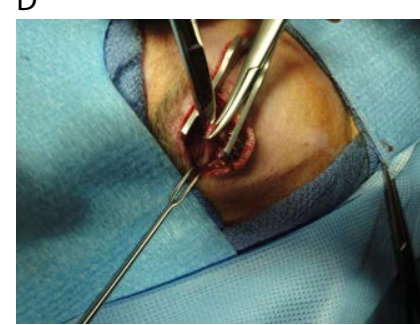

Figure 1: A) Ten years of pain following baseball injury to the right forehead/ supraorbital ridge. Note blue dot at neuroma site and healed vertical scar. B) Supraorbital nerve (SO) identified within the orbit. C) Neuroma dissected from supraorbital ridge location and still on intact SO nerve prior to transection of the nerve. D) Scissors shown in position to divide the gently retracted SO nerve.
A

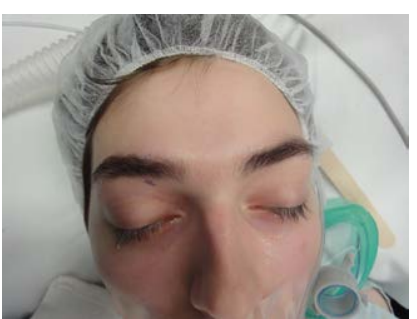

C

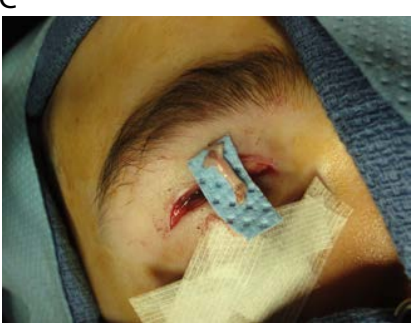

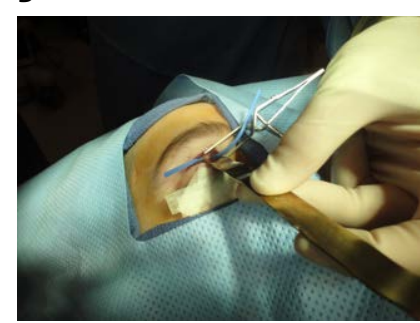

D

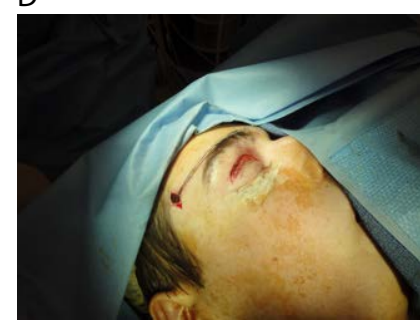

Figure 2: A) Twelve years of pain following baseball injury to the right forehead/ supraorbital ridge. Note blue dot at neuroma site and healed transverse scar. B) Supraorbital nerve (SO) identified within the orbit. C) The resected specimen without the neuroma attached. D) The peripheral nerve stimulator being removed. 
patients included in this report, there was an actual direct injury. When the physical examination demonstrates decreased forehead sensation, and trigger points for the pain are located at the site of injury overlying the SO and ST nerves, and this pain can be relieved by nerve block, the diagnosis is a neuroma. Compression of the SO and ST can occur in the absence of trauma if there is a tumor present, or a very narrow supra-orbital bone notch, or indeed an actual bone foramen [16] The history would not have trauma included. There would still be a trigger point. The pain from either a neuroma or chronic compression can cause frontal headaches. The frontal migraine patient usually has a long

A

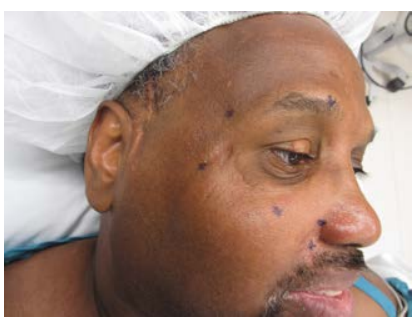

B

C
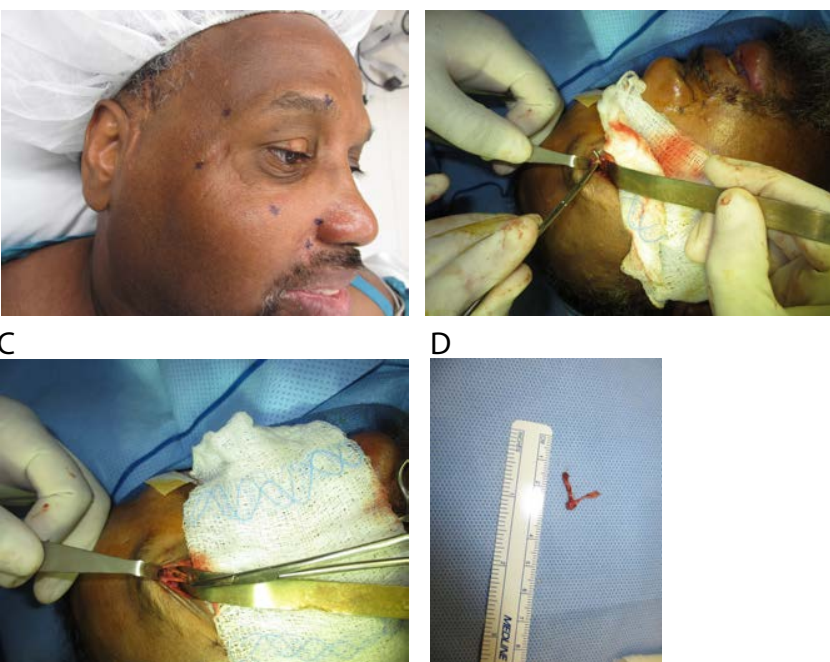

$\mathrm{D}$

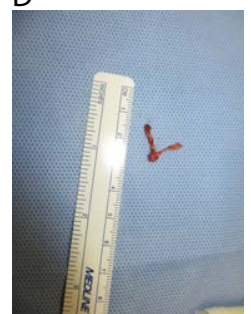

Figure 3: A) Five years after craniofacial, work-related trauma with orbita reconstruction of facial fractures. Note blue mark over supraorbital nerves, and also over zygomaticofacial, zygomaticotemporal and infraorbital nerves. B) Identification of SO within orbit. C) Resection of SO within orbit. D) SO nerve resected without neuroma.
A

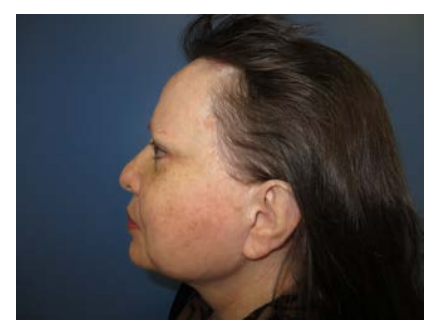

C

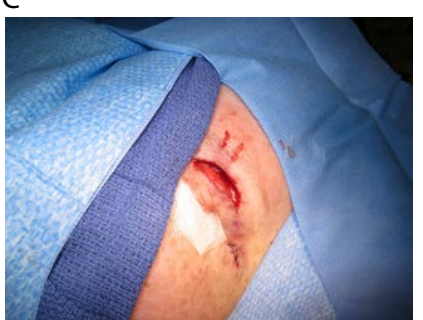

B

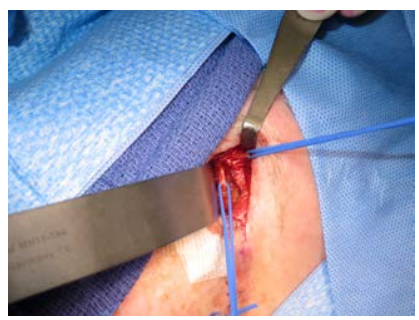

D

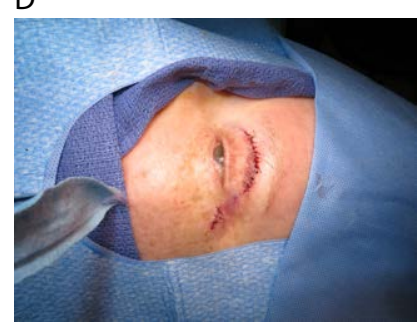

Figure 4: A) Two years after a second browlift, tightness of the forehead skin can be seen. B) Identification of supraorbital (SO) and supratrochlear (ST) nerves. C) Each resected nerve is noted on the skin. Each has suffered a stretch/traction injury. D) Location of the incision in the supratarsal crease. The most lateral incision was used to resect the zygomaticofacial nerve injured during fat grafting.
A

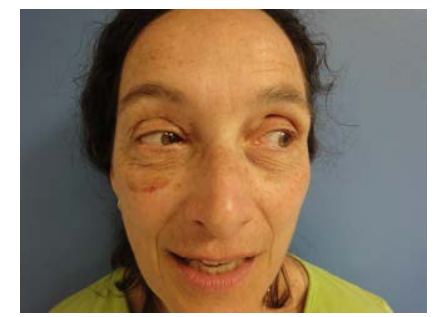

C

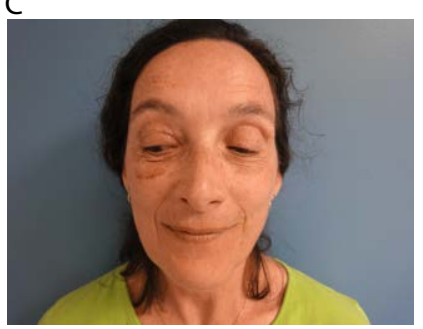

B

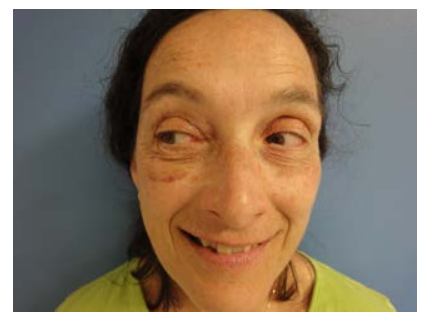

$\mathrm{D}$

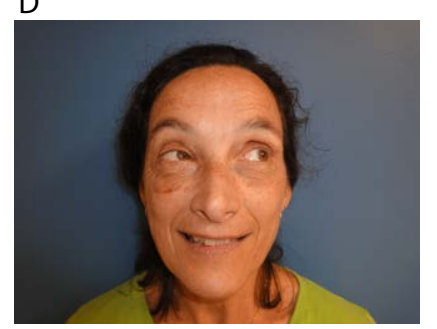

Figure 5: Demonstration of full range of extra-ocular muscles post-operatively without any associated pain. A) Gaze left. B) Gaze right. C) Gaze lower right. D) Gaze upper left.

history of headaches, there may be a familial history, the problem may be bilateral and associated with occipital headaches, the pain is often disabling, and the patient will have tried various diets and traditional headache medical remedies. With this history, if there are still SO and ST trigger points, and the headaches have been relieved temporarily by either a nerve block or botox injected into the corrugator muscle, then a neurolysis of the SO and ST nerves is surgically indicated [17-19] (Figure 4A-4D).

The surgical approach described here requires experience and delicate technique, as well as microsurgical technique in order to avoid cosmetic deformity, bleeding, injury to the eyeball itself, or scar that may interfere with the range of motion of the extra-ocular muscles.

In none of the patients was there pain with any field of gaze.

The limitation of this study is the small number of patients reported, however this is a rare traumatic location for chronic pain from neuroma of the trigeminal nerve.

\section{Conclusion}

An approach is reported to resect surgically neuroma of the supraorbital and supra-trochlear nerves, placing the proximal end of these nerves within the orbit. With a sufficiently long follow-up of 19.6 months, this group of 5 patients experience significant relief without complications.

\section{References}

1. Hong W (1990) [Applied anatomy of supraorbital and supratrochlear incisure or foramen of Chinese people]. Zhonghua Zheng Xing Shao Shang Wai Ke Za Zhi 6: 194-196.

2. Knize DM (1995) A study of the supraorbital nerve. Plast Reconstr Surg 96: 564-569.

3. Andersen NB, Bovim G, Sjaastad O (2001) The frontotemporal peripheral nerves. Topographic variations of the supraorbital, supratrochlear and auriculotemporal nerves and their possible clinical significance. Surg Radiol Anat 23: 97-104.

4. Erdogmus S, Govsa F (2007) Anatomy of the supraorbital region and the evaluation of it for the reconstruction of facial defects. J Craniofac Surg 18: 104-112. 
Citation: Dellon AL (2014) Treatment Strategy for Post-Traumatic Supraorbital and Supratrochlear Neuroma. J Trauma Treat 3: 213. doi:10.4172/21671222.1000213

5. Wilhelmi BJ, Mowlavi A, Neumeister MW, Blackwell SJ (2003) Facial fracture approaches with landmark ratios to predict the location of the infraorbital and supraorbital nerves: an anatomic study. J Craniofac Surg 14: 473-477.

6. Janis JE, Ghavami A, Lemmon JA, Leedy JE, Guyuron B (2008) The anatomy of the corrugator supercilii muscle: part II. Supraorbital nerve branching patterns. Plast Reconstr Surg 121: 233-240

7. Konofaos P, Soto-Miranda MA, Ver Halen J, Fleming JC (2013) Supratrochlear and supraorbital nerves: an anatomical study and applications in the head and neck area. Ophthal Plast Reconstr Surg 29: 403-408.

8. Liu MT, Chim H, Guyuron B (2012) Outcome comparison of endoscopic and transpalpebral decompression for treatment of frontal migraine headaches. Plast Reconstr Surg 129: 1113-1119.

9. Guyron, B, Kreigler, JS, Davis, J, Amini, SB (2009) Five year outcome of surgical treatment of migraine headache, Plast Reconstr Surg 124:11-16.

10. Siemionow M, Gharb BB, Rampazzo A (2011) Pathways of sensory recovery after face transplantation. Plast Reconstr Surg 127:1875-1889.

11. Kung TA, Guyuron B, Cederna PS (2011) Migraine surgery: a plastic surgery solution for refractory migraine headache. Plast Reconstr Surg 127: 181-189.

12. Ducic I, Larson EE (2008) Posttraumatic headache: surgical management of supraorbital neuralgia. Plast Reconstr Surg 121: 1943-1948.
13. Evans GR, Dellon AL (1994) Implantation of the palmar cutaneous branch of the median nerve into the pronator quadratus for treatment of painful neuroma. J Hand Surg Am 19: 203-206.

14. Dellon AL, Aszmann OC (1998) Treatment of superficial and deep peroneal neuromas by resection and translocation of the nerves into the anterolateral compartment. Foot Ankle Int 19: 300-303.

15. Dellon AL, Aszmann OC (1998) Treatment of superficial and deep peroneal neuromas by resection and translocation of the nerves into the anterolateral compartment. Foot Ankle Int 19: 300-303.

16. Boldrey E (1943) Amputation Neuroma in Nerves Implanted in Bone. Ann Surg 118: 1052-1057.

17. Guyuron B (2012) Discussion: The anatomical morphology of the supraorbital Notch: clinical relevance to the surgical treatment of migraine headaches. Plast Reconstr Surg 130: 1234

18. Guyuron B, Tucker T, Davis J (2002) Surgical treatment of migraine headaches. Plast Reconstr Surg 109: 2183-2189.

19. Guyuron B, Reed D, Kriegler JS, Davis J, Pashmini N, et al. (2009) A placebocontrolled surgical trial of the treatment of migraine headaches. Plast Reconstr Surg 124: 461-468. 